\section{Dicke Zwerge verdienen schlecht}

Schlanke Riesen verdienen mehr als dicke Zwerge - so lassen sich Erkenntnisse übersetzen, nach denen es Korrelationen zwischen Körpergröße, BMI und sozioökonomischem Status gibt. Laut einer Studie, bei der Forscher auf Daten von ca. 120.000 Personen zurückgriffen, kann auf ein Mitwirken der Gene an diesem Zusammenhang geschlossen werden. Dies bedeutet ein genetisches Einkommensplus von knapp 1.500 Euro pro Jahr je ca. $6,5 \mathrm{~cm}$ höherer Körperlänge verglichen zum Standard.

Tyrrell J. et al. BMJ 2016

\section{Aktives Leben schützt vor Demenz}

Finnische Wissenschaftler untersuchten bei Zwillingspaaren, inwieweit sich körperliche Aktivität auf die Demenzinzidenz auswirkt. Von 1975 bis 1981 wurde die Aktivität von 21.791 Personen gemessen. Bis 2011 starben 353 Teilnehmer durch Demenz. Das Risiko war bei aktiveren Personen um 35\% niedriger. Wenn Zwillingspaare isoliert betrachtet wurden, konnte körperliche Aktivität das Demenzrisiko sogar um $52 \%$ senken.

MMW - Fortschritte der Medizin 2015/17

\section{Arme Krebspatienten sterben früher}

Susanne Singer aus Mainz analysierte die Daten von 1.000 Krebspatienten, von denen viele ein fortgeschrittenes Tumorstadium erreicht hatten. Fazit: niedriges Einkommen und fehlende Erwerbstätigkeit beeinflussen das Tumorstadium entscheidend. Die sozioökonomischen Verhältnisse scheinen auch das Überleben zu beeinflussen. Die schlechteste Überlebensrate haben bei 21 von 25 Krebsarten Patienten, die in Regionen mit hoher sozioökonomischer Deprivation leben.

www.aerztezeitung.de
Antientzündliche Wirkung

\section{Orale Antidiabetika für adipöse MS-Patienten}

Bei der Behandlung von Patienten mit Multipler Sklerose und metabolischem Syndrom mit Metformin oder Pioglitazon zeigten sich in einer argentinischen Studie antiinflammatorische Effekte.

Laura Negrotto und Kollegen haben diese Hinweise an 50 MS-Patienten mit BMI > $30 \mathrm{~kg} / \mathrm{m}^{2}$ und metabolischem Syndrom untersucht. 20 Probanden erhielten 8501500 mg/d Metformin (M), zehn Patienten bekamen täglich 15-30 mg Pioglitazon (P) und 20 Personen blieben unbehandelt. Nach sechs Monaten zeigte sich in der Mund in der P-Gruppe ein Rückgang neuer oder sich vergrößernder Läsionen in der T2-Wichtung. Nach zwei Jahren waren sie unter $M$ von 2,5 zu Beginn auf 0,5 redu- ziert, unter $\mathrm{P}$ von 2,3 auf 0,6. Auch die gadoliniumangereicherten Herde hatten abgenommen (M: 1,8 vs. 0,1 ; P: 2,2 vs. 0,3 ). Zudem sanken die Werte von Leptin (M: 5,5 vs. $10,5 \mathrm{ng} / \mathrm{ml}$; P: 4,1 vs. 11,0 ), welches proinflammatorisch wirkt. Die Adiponektinspiegel hingegen stiegen (M: 15,4 vs. 4,5 ; P: 12,6 vs. 4,8 ). Adiponektin verfügt über antientzündliche Eigenschaften. Die Zahl der Interferon- $\gamma$ - und Interleukin (IL)-17-produzierenden Zellen war bei Patienten der M-Gruppe signifikant gefallen. Bei P-Patienten sank die Zahl der IL-6und Tumornekrosefaktor (TNF)-sezernierenden Zellen. Sowohl unter M als auch unter P verbesserten sich Zahl und Funktionen der T-Zellen.

(Christine Starostzik)

Negrotto N. et al. JAMA Neurol 2016 (online first)

\section{Hohe Genauigkeit \\ Bluttest auf Alzheimer?}

Mit einem speziellen Immuno-Infrarotsensor lassen sich fehlgefaltete BetaAmyloid-Peptide im Blut präzise und früh nachweisen. Auch ein Test auf das Peptid A $\beta$-3-40 könnte den Alzheimernachweis per Serumanalyse erleichtern.

Prof. Jens Wiltfang, Uniklinik Göttingen, präsentierte neue Ansätze zur Alzheimerdiagnostik: im Serum lassen sich viele verschiedene Amyloid-Peptide nachweisen. Forscher können erkennen, ob diese pathologisch gefaltet sind. Von den BetaAmyloid-Peptiden ist neben Aß1-42 auch Aß-3-40 interessant. Es wird früh im Erkrankungsverlauf produziert. Über den Quotienten Aß1-42 zu Aß-3-40 können rund $80 \%$ der Patienten mit ersten kognitiven Beeinträchtigungen oder einer frühen Demenz klassifiziert werden. Die quantitative Massenspektrometrie liefert ähnlich genaue Ergebnisse. Hier ist der
Quotient aus einer Variante des AmyloidVorläuferproteins und Aß1-42 sehr aussagekräftig. Über einen ganz anderen Weg wollen Forscher Konzentrationen der Beta-Amyloid-Peptide im Blut nachweisen, die sehr leicht verklumpen. Ihre Konzentration dürfte bereits 10-15 Jahre vor der Demenzdiagnose steigen. Um sie nachzuweisen, wurde ein spezieller Immuno-Infrarotsensor entwickelt. Dabei richtet sich ein Antikörper gezielt gegen die Beta-Faltblatt-Strukturen, mit denen sich die Peptide zu langen Ketten und Klumpen verbinden - also gegen die „Klebestellen“. Per Infrarot-Nahfeldspektroskopie lässt sich das Ergebnis auswerten: Kleben Beta-Faltblätter am Antikörper, verschiebt sich das Infrarotspektrum. Die diagnostische Genauigkeit für eine Alzheimerpathologie soll bei $84 \%$ (Blut) und 90\% (Liquor) liegen, so Wiltfang.

(Elke Oberhofer) 